\title{
Functional Metabolic Mapping During Forelimb Movement in Rat. II. Stimulation of Forelimb Muscles
}

\author{
Emily M. Santori, Terry Der, and Robert C. Collins \\ Department of Neurology and Neurological Surgery and the McDonnell Center for the Study of Higher \\ Brain Functions, Washington University, St. Louis, Missouri 63110
}

\begin{abstract}
Repetitive electrical stimulation of wrist extensor muscles in rat was combined with quantitative ${ }^{14} \mathrm{C}$-deoxyglucose autoradiography to study sensory systems functionally activated during forelimb movement. Metabolism increased ipsilaterally in the wrist extensors, the dorsal horn of the cervical spinal cord, the cuneate nucleus and cerebellar hemisphere. The metabolic activation in cerebellum occurred in cortex surrounding the primary fissure anteriorly (lobules simplex and $V$ ), and the prepyramidal fissure posteriorly (lobules paramedian and copula pyramis). Metabolism was increased in both granule cell and molecular layers and was uniform throughout the zone of activation. Hindlimb stimulation primarily activated the medial aspect of copula pyramis, demonstrating the somatotopic specificity of changes. Forelimb stimulation also activated contralateral sites in the dorsal accessory nucleus of the inferior olive, ventrobasal thalamus, and SI and SII in cortex. Studies of the relationship between the magnitude of the response and the frequency of the stimulation revealed a positive correlation in muscle, dorsal horn and cuneate nucleus. Other activated sites only showed a significant change at the highest rates of stimulation.

Comparison of the pattern of metabolic activation during forelimb movements induced centrally (Collins et al., 1986) with the pattern induced peripherally revealed overlap primarily in the paramedian zone of anterior and posterior cerebellum, and the granular cortex of SI and SII. These studies suggest that forelimb movement initiated centrally would have considerable influence on feedback sensation from the moving limb in these sites.
\end{abstract}

Sensory pathways from the forelimb of the rat have been studied with anatomical (Brown et al., 1977; Giesler et al., 1984; Gross et al., 1979; Lund and Webster, 1967) and electrophysiological methods (Bower and Woolston, 1983; Donoghue and Wise, 1982; Hall and Lindholm, 1974; Joseph et al., 1978; Sanderson et al., 1984; Shambes et al., 1978). These studies have given a fairly detailed description of first-order and polysynaptic afferent projections responding to electrical or mechanical stimulation of the forelimb. Studies of projections to the cerebellum are a case in point. Micromapping techniques have revealed fine details of "fracture somatotopy" for tactile sensation in anterior and posterior lobules (Bower and Woolston, 1983; Joseph et al., 1978; Shambes ct al., 1978). In addition, when these studies are compared with anatomical tracer studies of olivocerebellar relationships (Brown, 1980; Campbell and Armstrong, 1983), a

\footnotetext{
Received May 13, 1985; revised Aug. 5, 1985; accepted Aug. 12, 1985.

We wish to thank Mrs. Pigg and Mrs. Chandler for their help in the preparation of the manuscript. This work was supported by the United States Public Health Service Grant NS 14834 and a Klingenstein Senior Fellowship (to R.C.C.).

Correspondence should be addressed to Dr. Robert C. Collins, Department of Neurology, Box 8111, Washington University Medical School, St. Louis, MO 63110.

Copyright (C) 1986 Society for Neuroscience $0270-6474 / 86 / 020463-12 \$ 02.00 / 0$
}

somatotopy for the rat's olive can be envisioned. Studies of projections beyond cerebellum (Faull and Carman, 1978; Yamamoto et al., 1979), together with somatotopic mapping of lemniscal projections through the ventrobasal complex of thalamus (Angel and Clarke, 1975; Davidson, 1965; Emmers, 1965), provide a fairly complete picture of afferent pathways from forelimb to cortex.

The present study was undertaken to determine how metabolism changes in these pathways during forelimb movement. In particular, we were interested in discovering how changes in functional metabolism in response to forelimb movements induced from the periphery compared and contrasted with forelimb movements induced by cortical stimulation (Collins et al., 1986). We organized our research to answer three questions. (1) Which central neuroanatomic sites are metabolically activated by stimulation of forelimb muscles? (2) What is the relationship betwecn the frequency of stimulation and the magnitude of the regional metabolic response? (3) What is the difference between the functional metabolic response of peripherally vs centrally induced forelimb movement? Preliminary results from these studies have appeared in abstract form (Der et al., 1983).

\section{Materials and Methods}

Male Sprague-Dawley rats weighing 300-400 gm were fasted overnight and then were anesthetized with halothane for the cannulation of the femoral artery and vein in preparation for quantitative ${ }^{14} \mathrm{C}$-deoxyglucose (DG) studies (Collins et al., 1986). A 0.01-in.-diameter wire insulated to the last $2 \mathrm{~mm}$ was threaded through a 28 -gauge needle, and a hook was made by bending the wire tip over the needle bevel. The needle was used to insert and secure the hook into the wrist extensor muscles (negative lead) and subcutaneously into the dorsum of the paw (positive lead). The needle was then withdrawn, leaving the leads in place. Similar procedures were used on the hindlimb to prepare a scparatc group of animals for hindlimb stimulation. Animals were allowed $2-2.5 \mathrm{hr}$ to recover from anesthesia while lightly restrained on a lead brick.

Limb muscles were stimulated at intensities sufficient to cause consistent extensor jerks at the wrist or ankle- $-0.1 \mathrm{msec}$ monophasic pulses at $10-12 \mathrm{~V}$. Stimulation frequency was varied from 2 to $10 \mathrm{pulses} / \mathrm{sec}$ (pps) for different groups of animals. Rates above 10 pps were not tested, in view of the possibility that this might cause discomfort. Rats were stimulated for $10 \mathrm{~min}$ before giving DG and then throughout the entire 50 min of tracer circulation to the time of sacrifice.

Muscle groups from the forelimbs were dissected, weighed, and digested overnight at $50^{\circ} \mathrm{C}$ in Protosol $(1 \mathrm{ml} / 0.1 \mathrm{gm}$ tissue; New England Nuclear). The concentration of radioactivity was determined by liquid scintillation spectrophotometry. Brain sections were processed for autoradiography, histology, and quantitative image analysis as described in Collins et al. (1986).

Results

\section{Changes in DG metabolism}

Forelimb stimulation

Repetitive stimulation of wrist extensor muscles at 10 pps resulted in increases in metabolism in muscle, spinal cord, brain 
Table 1. Local glucose utilization (mean $\mu \mathrm{mol} / \mathrm{gm} / \mathrm{min} \pm \mathrm{SEM}$ ) during stimulated forelimb movement at $10 \mathrm{pulses} / \mathrm{sec}$

\begin{tabular}{|c|c|c|c|c|}
\hline \multirow[b]{2}{*}{ Structure } & \multirow[b]{2}{*}{$\begin{array}{l}\text { Control } \\
(n-5) \\
\text { Bilateral } \\
\text { average }\end{array}$} & \multicolumn{3}{|c|}{ Experimental $(n=4-7)$} \\
\hline & & Ipsilateral & Contralateral & $\begin{array}{l}\text { Ipsilateral } \\
\text { minus } \\
\text { contra- } \\
\text { lateral }\end{array}$ \\
\hline \multicolumn{5}{|l|}{ Spinal cord } \\
\hline Dorsal horn & $0.57 \pm 0.06$ & $0.99 \pm 0.14^{a}$ & $0.49 \pm 0.06$ & $0.50^{b}$ \\
\hline Ventral horn & $0.57 \pm 0.06$ & $0.57 \pm 0.03$ & $0.51 \pm 0.06$ & 0.06 \\
\hline \multicolumn{5}{|l|}{ Brain stem } \\
\hline Cuneate & $0.82 \pm 0.09$ & $1.22 \pm 0.12$ & $0.77 \pm 0.08$ & $0.45^{b}$ \\
\hline External cuneate & $0.72 \pm 0.05$ & $0.86 \pm 0.12$ & $0.73 \pm 0.06$ & 0.13 \\
\hline Olive; dorsal accessory nucleus & $0.97 \pm 0.02$ & $1.02 \pm 0.20$ & $1.28 \pm 0.17$ & $-0.26^{b}$ \\
\hline \multicolumn{5}{|l|}{ Cerebellum } \\
\hline Copula pyramis & $1.01 \pm 0.11$ & $1.18 \pm 0.08$ & $0.78 \pm 0.07$ & $0.40^{b}$ \\
\hline Paramedian lobule & $0.90 \pm 0.10$ & $1.05 \pm 0.03$ & $0.74 \pm 0.05$ & $0.31^{b}$ \\
\hline Lobule V & $0.99 \pm 0.16$ & $1.09 \pm 0.11$ & $0.80 \pm 0.07$ & $0.29^{b}$ \\
\hline Simplex & $0.92 \pm 0.16$ & $0.94 \pm 0.09$ & $0.71 \pm 0.04$ & $0.23^{b}$ \\
\hline \multicolumn{5}{|l|}{ Cortex } \\
\hline SI & $1.16 \pm 0.04$ & $1.06 \pm 0.08$ & $1.28 \pm 0.13$ & $-0.22^{b}$ \\
\hline SII & $1.13 \pm 0.03$ & $1.09 \pm 0.16$ & $1.28 \pm 0.17$ & $-0.19^{b}$ \\
\hline
\end{tabular}

${ }^{a} p<0.05$ vs control; least significant difference test.

${ }^{b} p<0.05$ vs opposite side; paired $t$ test.

stem, cerebellum, thalamus, and cortex (Table 1). In forelimb muscles there was a 10-fold increase in labcling in the stimulated wrist extensor muscles (dorsal forearm group) but no significant change from control for muscle groups of the ventral forearm or the biceps. Labeling in the stimulated muscles increased linearly with increasing frequency of stimulation up to $10 \mathrm{~Hz}$.

In the spinal cord, metabolic activation was restricted to the dorsal horn on the side ipsilateral to the stimulation. The most consistent zones of increased metabolism occurred in the medial aspect of Rexed laminae III-V (Fig. $1, A, B$ ). This zone was activated throughout the length of the cervical enlargement (Fig. $1 C)$. There was no consistent activation in the ventral horn.

In the medulla there was prominent activation of the ipsilateral cuneate nucleus (Fig. 2, $A-D$ ) but only mild activation of the lateral cuneate nucleus (Table 1). The contralateral inferior olive showed an increase in metabolism that was confined to the dorsal accessory nucleus (Fig. 2, E, F).

There was a prominent increase in metabolism in the ipsilateral cerebellar hemisphere. Separate sites were activated in the paramedian zone of the anterior and posterior hemisphere. To determine which lobules were involved, cerebella from different animals were prepared for analysis in the coronal, horizontal, and sagittal planes (Figs. 3 and 4). This revealed a pattern of activation that surrounded individual fissures rather than being organized in a strict lobule pattern. In the posterior paramedian zone the area of activation occurred within cerebellar cortex that surrounded the prepyramidal fissure (nomenclature of Larsell, 1952; Figs. 1-3). This involved the lateral aspect of the copula pyramis and the medial aspect of the paramedian lobule. Anteriorly, metabolism increased in cortex that surrounded fissura prima, i.e., the lateral aspect of lobule 5 and the medial aspect of the simplex lobule. In both the anterior and posterior sites of activation, metabolism was increased primarily in the depths of the fissure and did not extend to the lateral tips of the respective lobules. This pattern was seen best on the parasagittal and horizontal preparations (Fig. 4, $C, E$,
$F$ ). We found no consistent change in metabolism in the cerebellar vermis or deep nuclei.

In each stimulated animal, metabolism increased more in the posterior cerebellar zones compared with the anterior zones (Table 1). Individual laminae were examined in detail in the posterior zones (Fig. 5). At 10 pps, metabolism increased 1.4to 1.6 -fold in both the granule cell layer and overlying molecular layer. White matter subadjacent to the activated zones in each folia increased approximately 1.2 -fold. The magnitude of change in the granule cell layer was uniform throughout the entire field of activation.

At high rates of stimulation there was focal activation of the contralateral thalamus and sensorimotor cortex (Fig. 6). Thalamic activation was restricted to a spot in the posterior aspect of the ventrobasal nucleus. This was apparent in only a few animals. Activation of cortex was found in both SI and SII (Fig. 6, $C$ and $D$, arrows). The pattern in SI extended to the medial edge of the granule cells, which would include the sensorimotor overlap zone for the forelimb (Fig. 8). The magnitude of the response was as strong in SII as SI. There was no evidence for activation within the hemisphere ipsilateral to the stimulated forelimb.

\section{Hindlimb stimulation}

Stimulation of hindlimb extensors at 10 pps commonly resulted in fatigue. For this reason, labeling experiments were performed without a warmup period, and the intensity of stimulation was kept lower than during forelimb experiments (mean of 6 vs 12 V). With this strategy, accentuated labeling could be found in the lumbar spinal cord (Fig. 7A), gracile nucleus (not shown), cerebellum, and cortex (Fig. $7, B, C$ ). Activation of ipsilateral cerebellum was greatest in the medial aspect of copula pyramis of the posterior lobe (Fig. $7 B$ ). Cortical activation was found in SI, with accentuation of layers IV and $\mathrm{Vb}$ (Fig. $7 C$ ). This cortical zone was posterior and medial to the area activated by forelimb stimulation (Fig. 8). There was no activation found in SII. 

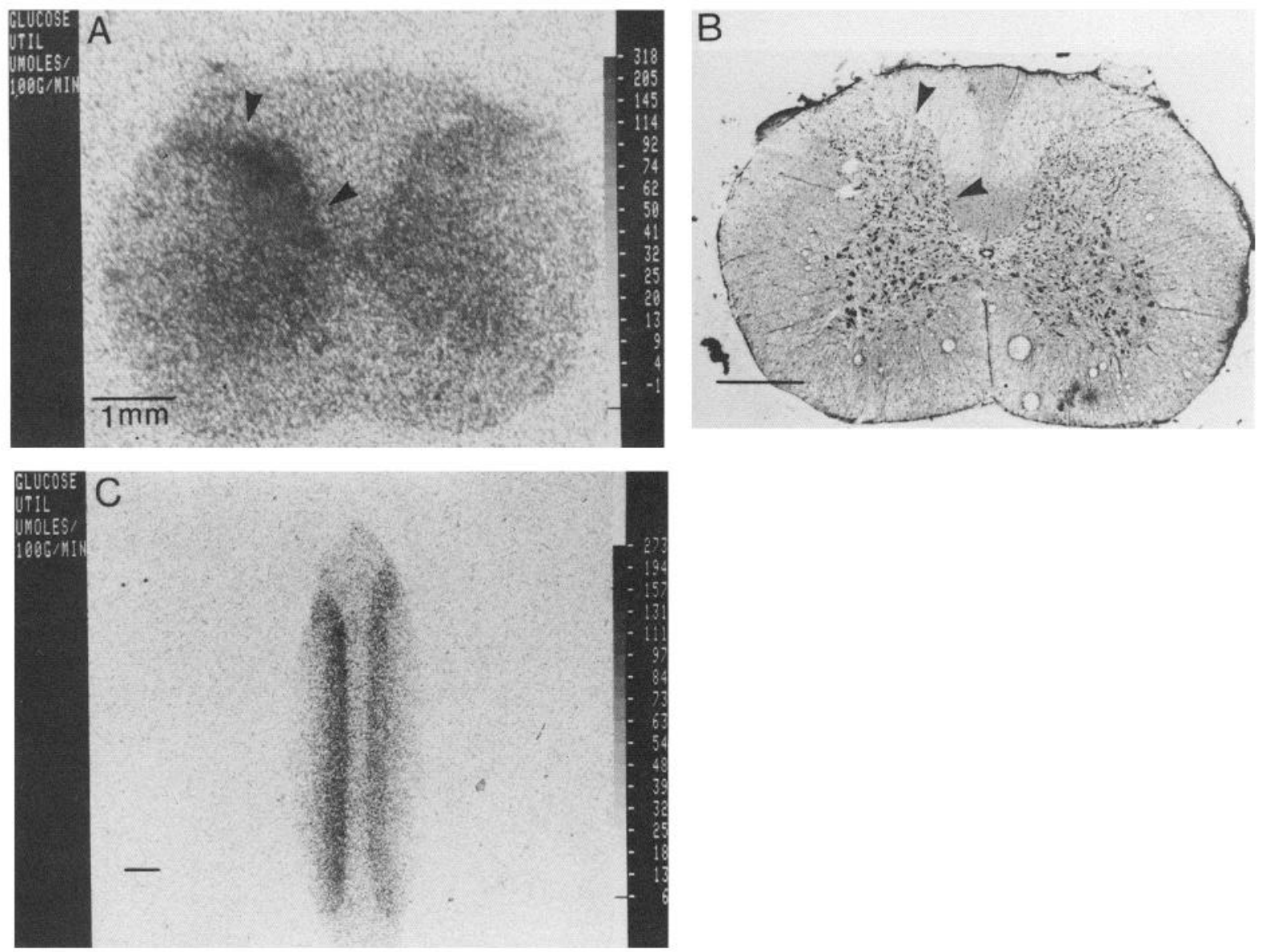

Figure 1. Changes in glucose utilization in spinal cord during forelimb muscle stimulation at 10 pps. $A$, The coronal section shows a DG autoradiogram that has been digitized and transformed with a pseudo-gray scale where increasing density represents increasing rates of glucose utilization. The scale on the right shows gray values in $\mu \mathrm{mol} / 100 \mathrm{gm} / \mathrm{min}$. The increase in metabolism was confined to the medial aspect of the dorsal horn between the arrows. B. The thionin stain of the adjacent section indicates that the zone of activation lies predominately in medial aspects of lamina III-V. $C$, Horizontal section through the dorsal horn from another animal stimulated at the same rate. The metabolic response occurred throughout the cervical enlargement. Scale bar, $1 \mathrm{~mm}$ for $A-C$.

\section{Metabolic response vs stimulation rate}

The effect of increasing the rate of forelimb stimulation on the magnitude of glucose utilization was studied in awake animals. Increasing the frequency up to $10 \mathrm{~Hz}$ resulted in an absolute increase in glucose consumption $(\mu \mathrm{mol} / \mathrm{gm} / \mathrm{min})$ in the dorsal horn of the spinal cord and the cuneate nucleus (Fig. 9A). This reached statistical significance in the dorsal horn using $10 \mathrm{~Hz}$. In the granule cell layer of the copula pyramis the response actually decreased in absolute magnitude between 5 and $10 \mathrm{~Hz}$ stimulation, and no clear rate-response relationship could be demonstrated.

The metabolic rate-response relationship also was studied by the method of "internal controls." Brain structures presumably uninvolved by the stimulus (septal nuclei, superficial layers of the superior colliculus, and medial geniculate) were measured in each animal. The mean value of glucose utilization for these areas was then divided into each value of the stimulated areas. This fraction, or ratio, is an expression of the relative increase in metabolism in the stimulated pathway compared with unstimulated sites in each animal (Sharp et al., 1983; Toga and Collins, 1981). When our data are expressed this way, a linear metabolic rate-response is seen for dorsal horn, cuneate, and copula pyramis (Fig. 9B).

\section{Functional metabolism of forelimb movement: central vs peripheral stimulation}

When the metabolic pattern of response induced by stimulating forelimb movement centrally (Collins et al., 1986) is compared with that induced by stimulating forelimb movement peripherally, several interesting features emerge. These are summarized in Figure 10. The areas of greatest overlap of metabolic pattern occurred on the "sensory side" of forelimb movement: dorsal horn, cuneate, cerebellum, and granular cortex. There was no peripherally induced activation, and thus no overlap, in basal ganglia, dorsal thalamus, or midbrain, sites that were affected by cortical stimulation. Activation occurred in ventrobasal thalamus only with intense peripheral stimulation and only with central stimulation that included granular zones of SI.

\section{Discussion}

\section{Metabolic mapping}

Analysis of muscle with the DG technique has been used previously to determine patterns of activation of muscle groups (Rapoport et al., 1978; Sharp and Ryan, 1984) and individual muscle fibers (Toop et al., 1982). We analyzed forelimb muscles 



Figure 2. Changes in glucose utilization in the cuneate nucleus and inferior olive. $A$, This autoradiogram from a coronal section through the caudal medulla shows an increase in metabolism in the ipsilateral cuneate nucleus (single arrow) and the contralateral inferior olive (between arrows). $B$, Thionin stain shows the cuneate nucleus (arrow) and the dorsal accessory nucleus of the inferior olive. $C$ and $D$, Horizontal autoradiogram and thionin-stained section through the dorsal medulla indicating activation within the full length of the cuneate nucleus. $E$ and $F$, Horizontal sections through the ventral medulla showing the activation in the dorsal accessory nucleus of the olive. The dark areas seen anteriorly on the autoradiogram illustrate a normal degree of activation in the superior olives. Scale bar, $1 \mathrm{~mm}$ for $A-F$. 
in our experiments to determine the specificity of our stimulation techniques. An increase in DG uptake was restricted to the muscle group of the dorsal forearm receiving direct stimulation. Activation of muscle, tendon, and joint afferents associated with wrist extension jerks would comprise the main afferent stimulation centrally.

Previous investigators have found that direct stimulation of peripheral nerve in anesthetized rat (Kennedy et al., 1975; Piepmeier et al., 1983) and cat (Kauer and Stewart, 1977) causes an increase in DG labeling in the spinal cord confined to the dorsal horn. Proshansky et al. (1980) found that stimulation of the plantar cushion of anesthetized cat caused accentuated labeling primarily in the medial aspects of Rexed layers III and IV. They concluded that this pattern represented an increase in metabolism within the preterminal field of the large-diameter, fastconducting $\mathrm{A}(\mathrm{a}, \mathrm{b})$ afferent fibers. The similarity of the topographic pattern found in our work probably reflects metabolism in the first-order synaptic field of muscle and joint afferents activated by muscle twitches (Light and Perl, 1979). Of note, the corticospinal tract sends a major projection to this same zone (Brown, 1971).

Most studies now document that activation of motor units by either central (Collins et al., 1986; Sharp and Ryan, 1984) or peripheral (Piepmeier et al., 1983) stimulation does not cause an increase in metabolism within ventral horn in rat. By comparison, microstimulation of motor cortex in primate causes a discrete pattern of metabolic activation of ventral horn, consistent with a strong monosynaptic input (Kosar and Asanuma, 1984). This species difference emphasizes the point that the lack of a metabolic change cannot be used as evidence for lack of physiological change. In this case the site and density of innervation are important considerations (see below).

The increase in metabolism in the cuneate nucleus could represent both direct activation from forelimb afferents and polysynaptic relay from the dorsal horn (Giesler et al., 1984). The pattern of activation was relatively uniform throughout the length of the cuneate nucleus, consistent with the somatotopic distribution of the forelimb (Nord, 1967). There was no apparent accentuation of labeling in the posterior zones, where studies in cat have found units primarily responsive to proprioceptive, as opposed to exteroceptive, stimuli (Cooke et al., 1971). It is unclear whether a functional subdivision exists in rat, as early tracing studies indicated that both anterior and posterior zones project on thalamus (Lund and Webster, 1967).

We found evidence of modest activation within the external cuneate nucleus. Studies of this nucleus in cat indicate that it receives strong proprioceptive input from the forelimb and projects to both anterior and posterior paramedian zones (Rinvik and Walberg, 1975).

The intensity of labeling in the dorsal accessory nucleus of the inferior olive is consistent with mapping experiments in cat showing strong cuneo-olivary and spino-olivary projections to this nucleus (Boesten and Voogd, 1975; Groenewegen et al., 1975). Brown et al. (1977) have observed these connections in rat. There was no activation of the medial accessory olivary nucleus, which also receives a projection from these sites.

Forelimb projections to cerebellum have been extensively mapped in cat (for review, see Bloedel and Courville, 1981; Brodal and Kawamura, 1980) and partially mapped in rat (Shambes et al., 1978). In general, our findings confirm the known projections to both anterior and posterior paramedian zones. The topography of the metabolic changes is similar to the topography of projections from the dorsal accessory nucleus of the rat (Brown, 1980; Campbell and Armstrong, 1983). Activation of cuneocerebellar (Cooke et al., 1971) and spinocerebellar systems (Oscarson and Uddenberg, 1964) would also contribute to metabolic activation of cerebellum during fore-

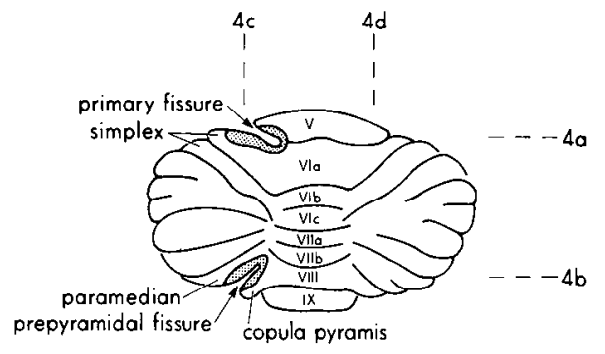

Figure 3. Summary figure of a dorsal vicw of the cerebellum showing the localization of changes in glucose utilization to the ipsilateral cerebellar hemisphere during forelimb stimulation (nomenclature of Larsell, 1952). The numbers $4 a-c$ indicate the plane of sections for the autoradiograms illustrated in Figure 4.

limb movement. There is considerable anatomic overlap in the projections of these systems (Ekerot and Larson, 1982; Murphy et al., 1973), but the present study does not allow us to determine the precise role of each system in creating the final pattern. Nevertheless, several points are of interest in this regard.

First, anterior and posterior cerebellar sites were always activated together, although the posterior sites were always more prominent. This double pattern could reflect, in part, activity ascending through axonal branches of mossy fibers (Cooke et al., 1971) and climbing fibers (Brodal et al., 1980) that project to the anterior and posterior zones. The functional consequence of generating two forelimb cerebellar zones remains unknown.

Second, the metabolic pattern was uniform throughout the zone of activation. There was no evidence for the fractured islands of activity that have been found with electrophysiological techniques used in "micromapping" forelimb afferent zones (Bower and Woolston, 1983; Joseph et al., 1978; Shambes et al., 1978). In the latter studies, punctate cutaneous stimuli were used, and responses were mapped predominately on the surfaces of folia. Sharp and Gonzalez (1985) found punctate zones of DG uptake in cerebellum in response to mechanical stimulation of whiskers. Our stimulation of muscle would have activated proprioceptive more than exteroceptive afferents. Stimulation of proprioceptive afferents in cat (muscle 1 A) has been found to cause diffuse activation within a folia (Cooke et al., 1971), with a greater response in the depths compared with the surface (Ekerot and Larson, 1972).

Third, it is of interest to note that the activated zones were organized around fissures, rather than within lobules. A principal advantage of the DG technique has been the ability to reconstruct and localize the full pattern of this activation. Functional studies of cerebellum traditionally emphasize localization by lobules. Our results suggest functional localization might also be considered as zones surrounding fissures. As the stimuli used in this study were relatively crude and intense, further experiments are necessary to determine whether such zones are a composite of many different and smaller receptive field zones activated from the moving forelimb.

Finally, our analysis of the cerebellum and its afferent systems failed to reveal consistent metabolic activation of several sites anticipated from previous anatomic and physiological studies. We found no changes in the lateral reticular nucleus of the brain stem (Brodal, 1975; Kunzle, 1973) or lobule IV, vermis 9A, or contralateral cerebellar cortex (Bloedel and Courville, 1982; Oscarsson, 1969; Shambes et al., 1978).

In consideration of sites beyond cerebellum, we failed to find activation in dorsal thalamic nuclei known to receive cerebellar nuclear output, in particular ventralis lateralis (Faull and Carman, 1978). Direct stimulation of cerebellar cortex in anesthetized rat causes short latency evoked potentials in cerebral cortex 

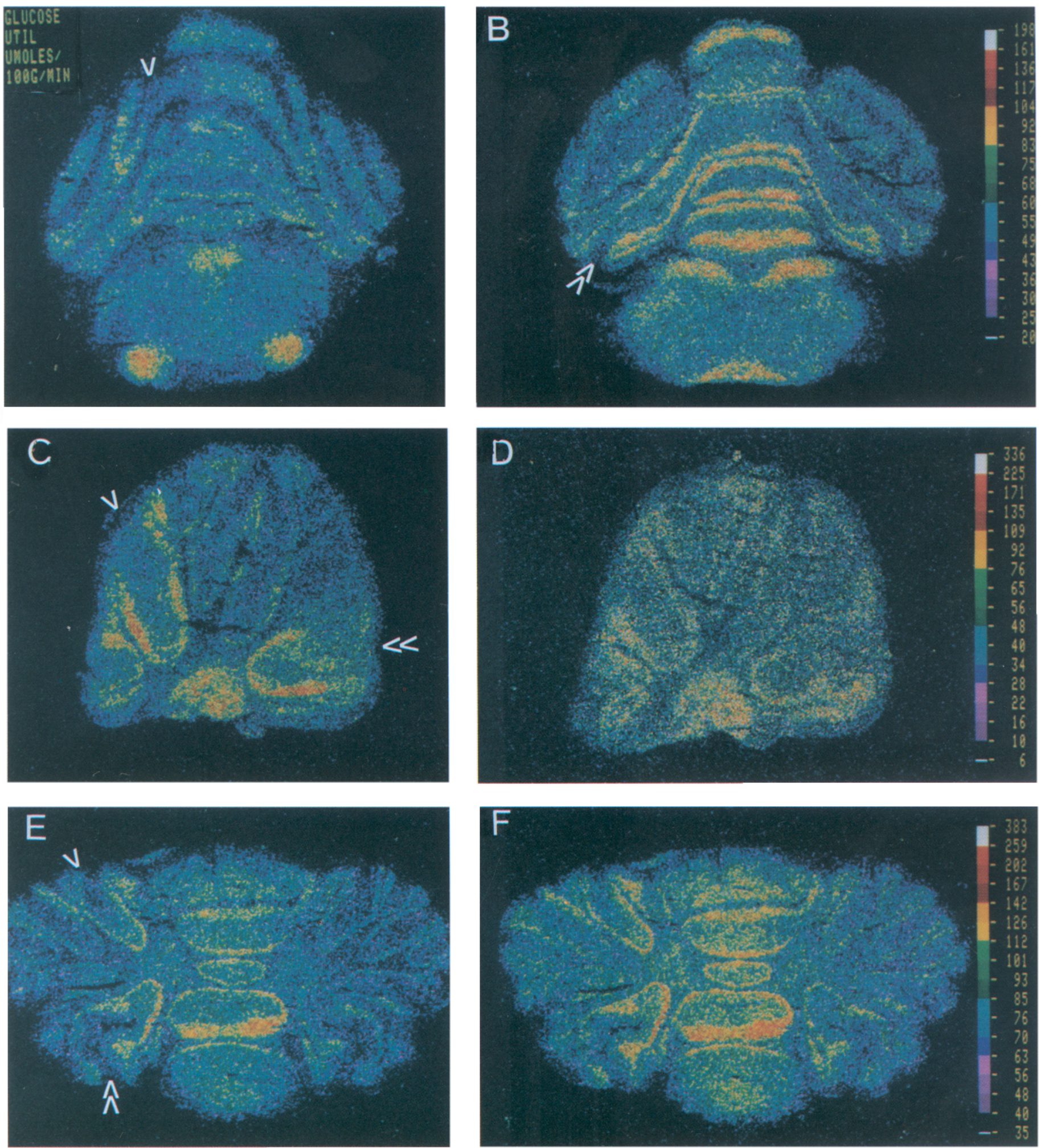

Figure 4. Pseudo-colored autoradiograms from the cerebella of three animals stimulated at 10 pps. Absolute rates of glucose utilization are indicated for each pair on the right. The increase in glucose utilization occurred in the anterior lobe around the primary fissure (single arrow) and in the posterior lobe around the prepyramidal fissure (double arrows). $A$ and $B$, Coronal sections, anterior on left. $C$ and $D$, Parasagittal sections, ipsilateral on left. $E$ and $F$, Horizontal sections, dorsal on left. Refer to Figure 3 for orientation. 
(Yamamoto et al., 1979). Cerebellothalamocortical relationships have been well studied in cat (Allen and Tsukahara, 1974; Sasaki et al., 1972). Intense, high-frequency train stimulation of cerebellar cortex can increase DG labeling diffusely throughout cerebellum and most projection pathways (Schim et al., 1981). Perhaps of more relevance to this study are Strick's findings in monkeys (1976) that passive manipulation of a limb changes neuronal firing only slightly in ventrolateral thalamus. In addition, firing patterns indicate reciprocal changes, where increased rates are commonly followed by transient suppression. Over the prolonged period of DG circulation there may be no net increase in DG metabolism compared with a steady-state control.

High rates of stimulation were necessary before an increase in metabolism in ventrobasal thalamus and somatosensory cortex was observed. The relative resistance of these areas to change probably reflects the nature of the stimulus. Angel and Clarke (1975) found that less than $10 \%$ of forelimb units in ventrobasal thalamus of rat responded to deep stimuli (heavy pressure) or joint movement, although muscle stimulation was not tested. In our experiments, there may have been only weak activation of cutaneous afferents from skin and hair even during vigorous forelimb movement. Even with this consideration in mind, however, the weak activation of VB stands in contrast to the strong activation of the cuneate nucleus. With regard to cortex, it is of interest that both SI and SII showed a similar degree of metabolic response, perhaps reflecting ascending activity from a common site in ventrobasal thalamus (Emmers, 1965). Tactile stimulation of the monkey's hand has been found to cause an increase in metabolism contralaterally in SI and bilaterally in SII (Juliano et al., 1981, 1983). Projections to SII are bilateral in rat, but the ipsilateral pathway is not robust (Emmers, 1965; Tomasulo and Emmers, 1970; Welker and Sinha, 1972), perhaps explaining our lack of DG change in the ipsilateral SII zone.

\section{Stimulation rate vs metabolic response}

Changes in glucose utilization rate within a site are thought to reflect local changes in functional activity (for review, see Sokoloff, 1984). The physiological events causing the metabolic changes are debated. Some investigators have noticed a good correlation between rates of neuronal firing and glucose utilization (Schoppman and Stryker, 1981; Theurich et al., 1984), while others have drawn attention to a correlation between changes in field potentials and glucose utilization (Auker et al., 1983). This latter study emphasized the relative high metabolic cost of ion pumping in synaptic beds, whether or not transsynaptic excitation and neuronal firing occur (see also Mata et al., 1980; Schwartz et al., 1979). A linear relationship exists between stimulus frequency of afferents to the sympathetic ganglion and changes in its rate of glucose utilization (Yarowsky et al., 1983).

Figure 5. Changes in glucose utilization in cerebellar layers within an active zone. The posterior paramedian zone of cortex surrounding the prepyramidal fissure was analyzed in detail in animals stimulated at 10 pps. The molecular, granular, and white matter layers were measured across the active zone on the ipsilateral side (open areas) and compared statistically against the same zones on the contralateral side (filled areas). $A$, Plot of data for glucose utilization by position of the cursor over the different layers. The magnitude of the stimulus-induced increase can be seen as the height of the white bars (ipsilateral) above the black bars (contralateral). ${ }^{*} p<0.05$, paired $t$ test. $B$, Representative autoradiogram showing the position of the windows used to measure changes. $C$, Thionin stain of the adjacent section showing the cortical layers. The dashed line indicates the prepyramidal fissure.
A

Figure 6. Activation of metabolism in thalamus and cortex during forelimb movement. $A$, Coronal autoradiogram showing an animal selected for the greatest degree of metabolic change in thalamus (arrow). B, Thionin stain showing the localization of the active zone within the ventrobasal nucleus (arrow). $C$, Anterior coronal section showing activation within the forelimb zone of SI cortex (arrow). Metabolism was increased the most in layer IV. Compare with the normal pattern on the ipsilateral side. $D$, Activation within SII (arrow) of the same animal. The vertical linear density in dorsal cortex in this section represents an artifact of cutting.

Figure 7. Changes in glucose utilization during hindlimb stimulation. $A$, Activation in the lumbar spinal cord was confined to the medial aspects of the dorsal horn. $B$, Cerebellum, horizontal autoradiogram. A zone of mild activation occurred in the ipsilateral copula pyramis (arrow). The bilateral dense structures seen anteriorly illustrate normal activation of the inferior colliculi. $C$, Activation of cortex occurred primarily in granular and infragranular layers of the hindlimb zone of SI (arrow).


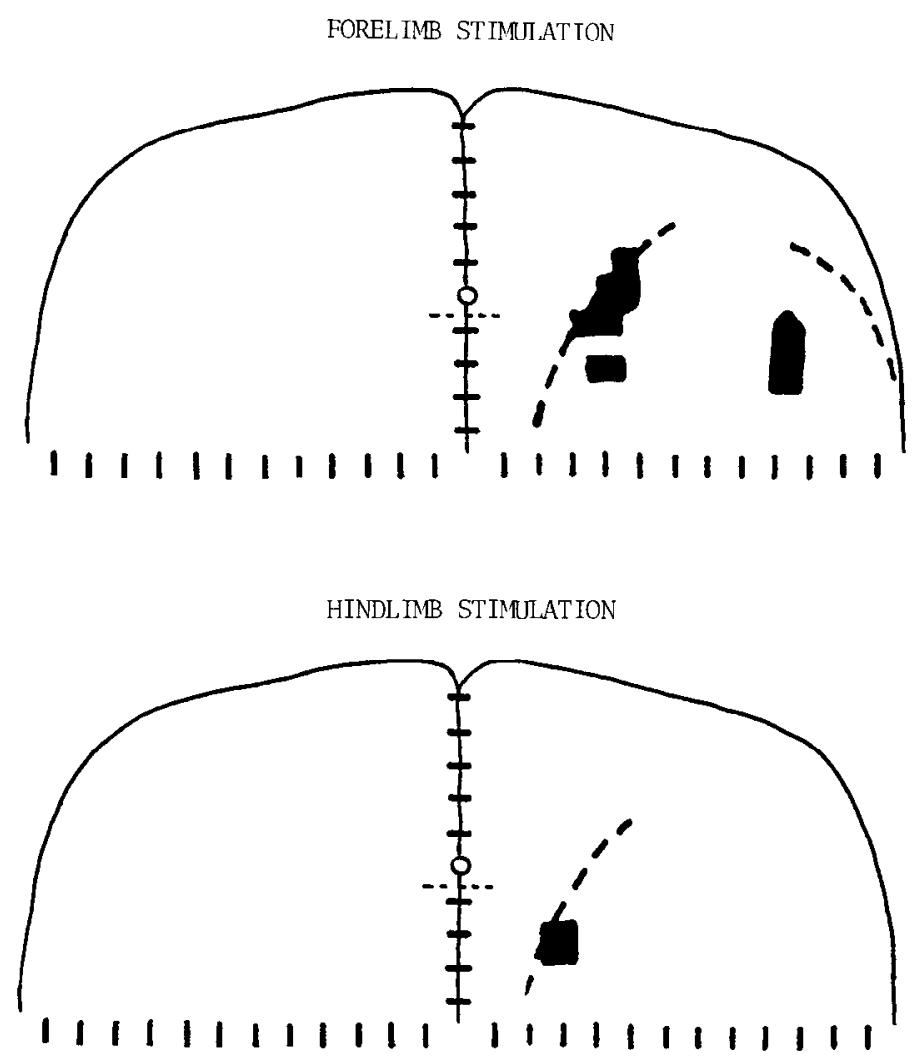

Figure 8. Topical maps of flattened rat cortex showing the zones of increased glucose utilization in response to stimulation of fore- and hindlimb muscles. The hash marks on the horizontal and midline axis indicate millimeter division. The circle on the midline indicates the anterior-posterior location of the anterior commissure, and the dashed line indicates the bregma. The dashed lines on the cortex, seen medially and laterally, represent the location of the medial edge of granular cortex and the rhinal fissure, respectively.

Other studies have documented a linear relationship between the intensity (Sokoloff, 1979) and the rate (Toga and Collins, 1981) of visual stimulation and changes in glucose utilization in central visual pathways.

There was a reasonably linear rate-response relationship in the first-order synaptic beds from stimulated muscle to medial aspects of dorsal horn and the cuneate nucleus. In some regards this can be considered as a result of nearly direct stimulation of peripheral fibers of the dorsal root ganglion cells subserving muscle contraction and joint movement. This relationship is similar to the in vivo studies of Yarowsky et al. (1983), as well as earlier in vitro work on the frequency dependency of peripheral nerve metabolism (Harkonen et al., 1969; Horowicz and Larrabee, 1958). We failed to find a simple rate-response beyond first-order synaptic beds. This is likely due in part to a decrement in physiological activity across sequential synapses. Local inhibitory circuits in sensory relay nuclei play a role in pacing synaptic transmission rates (Singer, 1977). In addition, central pathways are finely tuned to single receptive field properties or combinations thereof. Our stimulus may have been too crude to activate higher centers.

\section{Central vs peripheral stimulation}

Physiological studies in cat have documented the influence of the pyramidal tract on afferent sensory pathways in spinal cord (Andersen et al., 1964a), the cuneate nucleus (Andersen et al., 1964b; Jabbur and Towe, 1961), and the thalamus (Clare et al., 1964; Shimazu et al., 1965). It is estimatcd that $5-18 \%$ of pyramidal tract cells may send collaterals into one or more sites
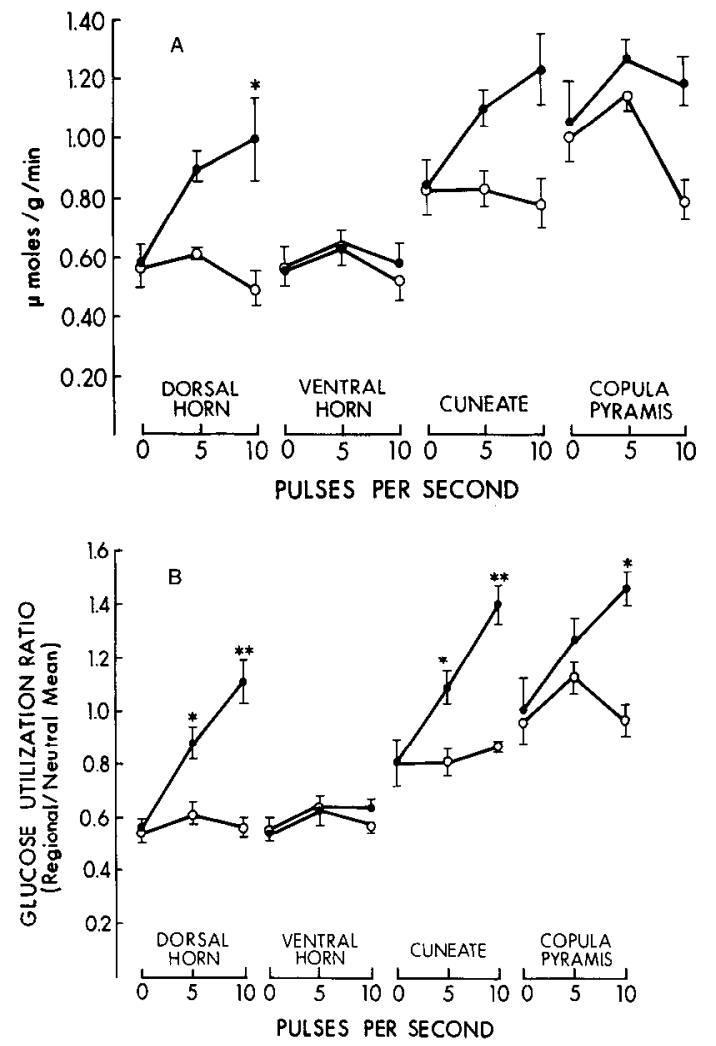

Figure 9. $A$, Changes in glucose utilization in response to increasing frequency of stimulation of forelimb muscles. $B$, Relative increase in glucose utilization in stimulated structures, correcting for internal changes in each animal by the method of ratios. ${ }^{*} p<0.05$ vs control; ${ }^{* *} p<$ 0.05 vs control and 5 pps (Duncan's multiple range test). Filled circles, Ipsilateral to stimulus. Open circles, Contralateral to stimulus.

while en route to the spinal cord (Endo et al., 1973). Although similar physiologic studies are lacking in rat, anatomical studies suggest that descending influences on sensation probably also exist in the cuneate and spinal cord (Brown, 1971; Valverde, 1966). Physiologic studies in cat (Allen et al., 1974) and rat (Bower et al., 1981) have found topographic projections from somatosensory cortex to cerebellar cortex, as well as to deep layers of superior colliculus (Kassel, 1982). Comparing the results of our two studies of central and peripherally induced forelimb movement, several interesting features emerge in light of these earlier studies.

First, there was a striking difference between the stimulation rates required to produce metabolic responses in the two studies. Cortical stimulation at $1 \mathrm{~Hz}$ produced prominent activation of central pathways, but no significant metabolic change occurred with peripheral stimulation until $5 \mathrm{~Hz}$ was reached. Part of the discrepancy is likely due to the type of stimulation used in each case. Repetitive train stimuli $(500 \mathrm{~Hz}$ for $20 \mathrm{msec})$ were applied to cortex, but only single shocks $(0.1 \mathrm{msec}$ duration) were applied to muscle. Thus, although the forelimb jerk movements were matched reasonably well for type and degree of movement, the central stimuli were, by necessity, stronger (Collins et al., 1986).

Second, in each study it was difficult to detect metabolic change in the most distant projection sites. As discussed above, failure to see a metabolic change cannot be used to rule out significant physiological activity. As a first approximation, a negative finding is best interpreted as insufficient flux of membrane ions to activatc cncrgy consumption to lcvels significantly above control for the duration of the experiment. Conversely, when ex- 

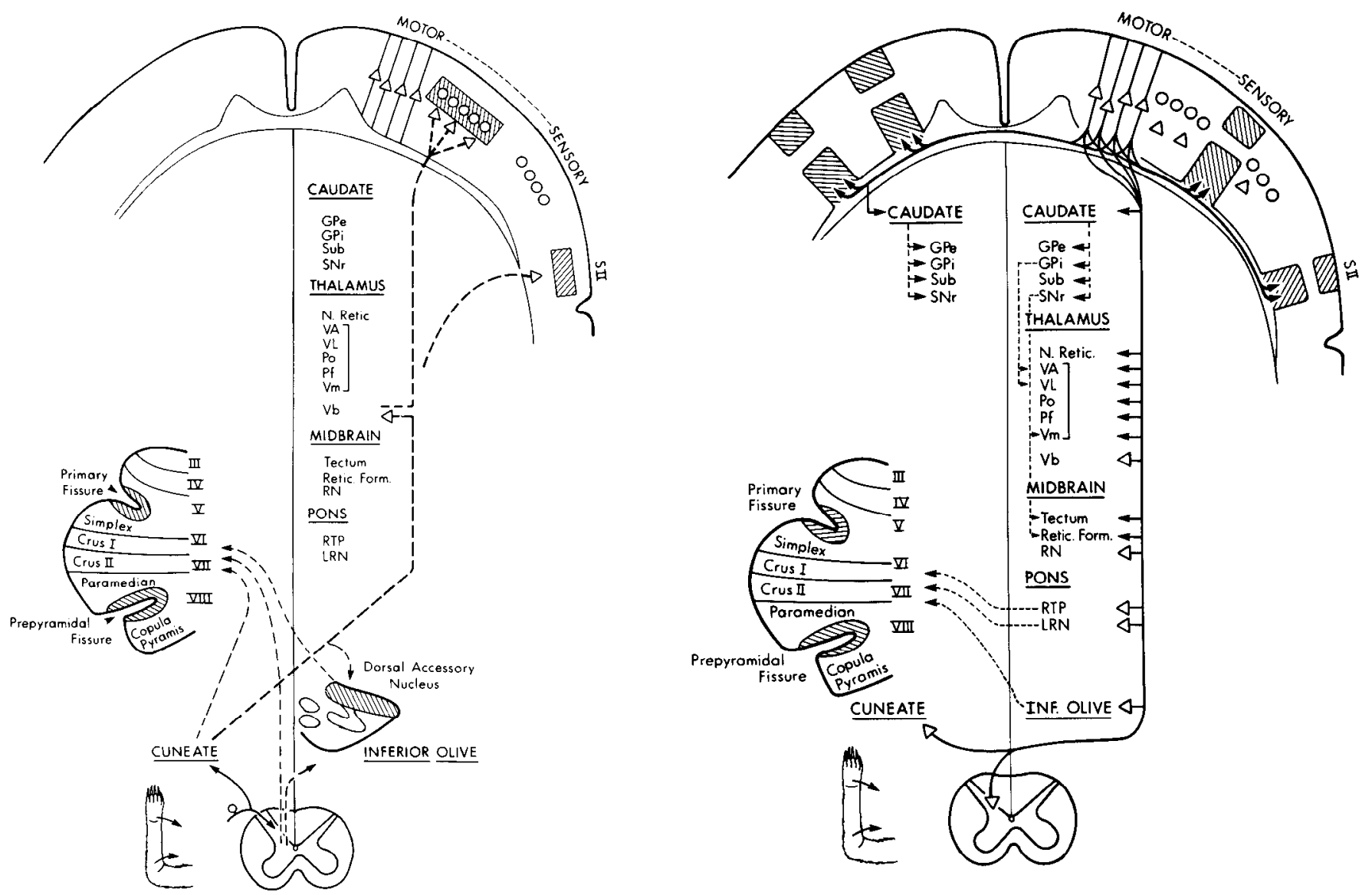

Figure 10. Summary of metabolic changes within forelimb pathways in response to (left) stimulation of muscle (afferent systems) or (right) motor cortex (efferent systems; see Collins et al., 1986). Solid lines, First-order connections. Dashed lines, Polysynaptic connections where metabolism changed. Solid arrowheads, Strong metabolic activation. Hollow arrowheads, Weak activation. Identical zones of activation occurred in anterior and posterior cerebellar cortex in the two studies. There was suggested overlap in spinal cord and the cuneate, but pure descending influences were relatively weak. There was overlap in SI and SII when afferent stimuli were strong.

cessive stimuli are necessary to produce a metabolic change within a particular site, it may teach little of the functional role that site may play in the induced behavior under observation.

With these considerations in mind, it is worth noting that the major sites of overlap in metabolic activation-comparing central and peripheral stimulation - occurred on the "sensory" side of forelimb movement, primarily in cerebellum and granular cortex. Evidence for weak metabolic overlap was suggested for dorsal horn and cuneate. This would seem to indicate that movements initiated centrally would influence activity "coming back" from the moving limb in these sites. We might cautiously propose that these metabolic data also suggest that sites in basal ganglia, thalamus, and midbrain do not participate in strong interactions in these type of experiments.

\section{References}

Allen, G. I., and N. Tsukahara (1974) Cerebrocerebellar communication systems. Physiol. Rev. 54: 957-1006.

Allen, G. I., G. B. Azzena, and T. Ohno (1974) Somatotopically organized inputs from forc- and hindlimb arcas of sensorimotor cortex to cerebellar purkyne cells. Exp. Brain Res. 20: 255-272.

Andersen, P., J. C. Eccles, and T. A. Sears (1964a) Cortically evoked depolarization of primary afferent fibers in the spinal cord. J. Neurophysiol. 27: 63-77.

Andersen, P., J. C. Eccles, R. F. Schmidt, and T. Yokota (1964b) Depolarization of presynaptic fibers in the cuneate nucleus. J. Neurophysiol. 27: 92-106.

Angel, A., and K. A. Clarke (1975) An analysis of the representation of the forelimb in the ventrobasal thalamic complex of the albino rat. J. Physiol. (Lond.) 249: 399-423.
Auker, C. R., R. M. Meszler, and D. O. Carpenter (1983) Apparent discrepency between single-unit activity and [14C]deoxyglucose labeling in optic tectum of the rattlesnake. J. Neurophysiol. 49: 15041516.

Beosten, A. J. P., and J. Voogd (1975) Projection of the dorsal column nuclei and spinal cord on the inferior olive in the cat. $J$. Comp. Neurol. 161: 215-238.

Bloedel, J. R., and J. Courville (1981) Cercbellar afferent systems. In Handbook of Physiology, Sec. 1, Vol. 2, Pt. 2, S. R. Geiger, ed., pp. 735-829, American Physiological Society, Bethesda, MD.

Bower, J. M., and D. C. Woolston (1983) Congruence of spatial organization of tactíle projections to granule cell and purkinje cell layers of cerebellar hemispheres of the albino rat: Vertical organization of cerebellar cortex. J. Neurophysiol. 49: 745-766.

Bower, J. M., D. H. Beermann, J. M. Gibson, G. M. Shambes, and W. Welker (1981) Principles of organization of a cerebro-cerebellar circuit. Micromapping the projections from cerebral (SI) to cerebellar (granule cell layer) tactile areas of rats. Brain Behav. Evol. 18: 1-18.

Brodal, A., and K. Kawamura (1980) Olivocerebellar projection: A review. Adv. Anat. 64: 1-140.

Brodal, A., F. Walberg, K. J. Berkeley, and A. Pelt (1980) Anatomical demonstration of branching olivocercbellar fibers by means of doublc retrograde labelling technique. Neuroscience 5: 2193-2202.

Brodal, P. (1975) Demonstration of a somatotopically organized projection onto the paramedian lobule and the anterior lobe from the lateral reticular nucleus: An experimental study with horseradish peroxidase. Brain Res. 95: 221-239.

Brown, J. T., V. Chan-Palay, and S. L. Palay (1977) A study of afferent input to the inferior olivary complex in the rat by retrograde axonal transport of horseradish peroxidase. J. Comp. Neurol. 176: 1-22.

Brown, L. T., Jr. (1971) Projections and terminations of the corticospinal tract in rodents. Exp. Brain Res. 13: 432-450. 
Brown, P. A. (1980) The inferior olivary connections to the cerebellum in the rat studied by retrograde axonal transport of horseradish peroxidase. Brain Res. Bull. 5: 267-275.

Campbell, N. C., and D. M. Armstrong (1983) Topographical localization in the olivocerebellar projection in the rat: An autoradiographic study. Brain Res. 275: 235-249.

Clare, M. H., W. M. Landau, and G. H. Bishop (1964) Electrophysiological evidence of a collateral pathway from the pyramidal tract to the thalamus in the cat. Exp. Neurol. 9: 262-267.

Collins, R. C., E. Santori, T. Der, A. W. Toga, and E. W. Lothman (1986) Functional metabolic mapping during forelimb movement in rat. I. Stimulation of motor cortex. J. Neurosci. 6: 448-462.

Cooke, J. D., B. Larson, O. Oscarsson, and B. Sjölund (1971) Origin and termination of cuneocerebellar tract. Exp. Brain Res. 13: 339358

Davidson, N. (1965) The projection of afferent pathways on the thalamus of the rat. J. Comp. Neurol. 124: 377-390.

Der, T., E. S. Santori, and R. C. Collins (1983) Functional cerebellar metabolism during forelimb movement in the rat. Neurosci. Abstr. 9: 224.

Donoghue, J. P., and S. P. Wise (1982) The motor cortex of the rat: Cytoarchitecture and microstimulation mapping. J. Comp. Neurol. 212: 76-88.

Ekerot, C.-F., and B. Larson (1972) Differential termination of the exteroceptive and proprioceptive components of the cuneocerebellar tract. Brain Res. 36: 420-424.

Ekerot, C.-F., and B. Larson (1980) Termination in overlapping sagittal zones in cerebellar anterior lobe of mossy and climbing fiber paths activated from dorsal funiculus. Exp. Brain Res. 38: 163-172.

Ekerot, C.-F., and B. Larson (1982) Branching of olivary axons to innervate pairs of sagittal zones in the cerebellar anterior lobe of the cat. Exp. Brain Res. 48: 185-198.

Emmers, R. (1965) Organization of the first and the second somesthetic regions (SI and SII) in the rat thalamus. J. Comp. Neurol. 124: 215-228.

Endo, K., T. Araki, and N. Yagi (1973) The distribution and pattern of axon branching of pyramidal tract cells. Brain Res. 57: 484-491.

Faull, R. L. M., and J. B. Carman (1978) The cerebellofugal projections in the brachium conjunctivum of the rat. I. The contralateral ascending pathway. J. Comp. Neurol. 178: 495-518.

Giesler, G. J., Jr., R. L. Nahin, and A. M. Madsen (1984) Postsynaptic dorsal column pathway of the rat. I. Anatomical studies. J. Neurophysiol. 51: 260-275.

Groenewegen, H. J., A. J. P. Beosten, and J. Voogd (1975) The dorsal column nuclear projection to the nucleus ventralis posterior lateralis thalami and the inferior olive in the cat. J. Comp. Neurol. 162: 505518.

Gross, M. H., J. A. Fox, and J. D. Curtis (1979) A horseradish peroxidase study of primary afferent projections to the medullary cuneate nucleus in the rat. Neurosci. Lett. 14: 147-153.

Hall, R. D., and E. P. Lindholm (1974) Organization of motor and somatosensory neocortex in the albino rat. Brain Res. 66: 23-38.

Härkönen, M. H. A., J. V. Passonneau, and O. H. Lowry (1969) Relations between energy reserves and function in rat superior cervical ganglion. J. Neurochem. 16: 1439-1450.

Horowicz, P., and M. G. Larrabee (1958) Glucose consumption and lactate production in a mammalian sympathetic ganglion at rest and in activity. J. Neurochem. 2: 102-118.

Jabbur, S. J., and A. L. Towe (1961) Cortical excitation of neurons in dorsal column nuclei of the cat, including an analysis of pathways. J. Neurophysiol. 24: 499-509.

Joseph, J. W., G. M. Shambes, J. M. Gibson, and W. Welker (1978) Tactile projections to granule cells in caudal vermis of the rat's cerebellum. Brain Behav. Evol. 15: 141-149.

Juliano, S. L., P. J. Hand, and B. L. Whitsel (1981) Patterns of increased metabolic activity in somatosensory cortex of monkeys $\mathrm{Ma}$ caca fascicularis, subjected to controlled cutaneous stimulation: A 2-deoxyglucose study. J. Neurophysiol. 46: 1260-1284.

Juliano, S. L., P. J. Hand, and B. L. Whitsel (1983) Patterns of metabolic activity in cytoarchitectural area SII and surrounding cortical fields of the monkey. J. Neurophysiol. 50:961-980.

Kassel, J. (1982) Somatotopic organization of SI corticotectal projections in rats. Brain Res. 231: 247-255.

Kauer, J. S., and W. B. Stewart (1977) Localized uptake of 14C-2deoxyglucose in cat spinal cord and dorsal column nuclei in response to sciatic nerve stimulation. Neurosci. Abstr. 3: 503.
Kennedy, C., M. H. desRosiers, M. Reivich, F. Sharp, J. W. Jehle, and L. Sokoloff (1975) Mapping of functional neural pathways by autoradiographic survey of local metabolic rate with [14C]deoxyglucose. Science 187: 850-853.

Kosar, E., and H. Asanuma (1984) Focal and diffuse metabolic changes in the spinal cord of the monkey elicited by microstimulation of differing cortical foci. Brain Res. 310: 43-54.

Kunzle, H. (1973) The topographic organization of spinal afferents to the lateral reticular nucleus of the cat. J. Comp. Neurol. 149: 103116.

Larsell, O. (1952) The morphogenesis and adult pattern of the lobules of the cerebellum of the white rat. J. Comp. Neurol. 97: 281-356.

Light, A. R., and E. R. Pcrl (1979) Recxamination of the dorsal root projection to the spinal dorsal horn including observations on the differential termination of coarse and fine fibers. J. Comp. Neurol. 186: 117-132.

Lund, R. D., and K. E. Webster (1967) Thalamic afferents from the dorsal column nuclei. An experimental study in the rat. J. Comp. Neurol. 130: 301-312.

Mata, M., D. J. Fink, H. Gainer, C. B. Smith, L. Davidson, H. Savaki, W. J. Schwartz, and L. Sokoloff (1980) Activity dependent energy metabolism in rat posterior pituitary primarily reflects sodium pump activity. J. Neurochem. 34: 213-215.

Murphy, J. Y., W. A. MacKay, and F. Johnson (1973) Differences between cerebellar mossy and climbing fibre responses to natural stimulation of forelimb muscle proprioceptors. Brain Res. 55: 263289.

Nord, S. G. (1967) Somatotopic organization in the spinal trigeminal nucleus, the dorsal column nuclei and related structures in the rat. J. Comp. Neurol. 130: 343-356.

Oscarsson, O. (1969) Termination and functional organization of the dorsal spino-olivocerebellar path. J. Physiol. (Lond.) 200: 129-149.

Oscarsson, O., and N. Uddenberg (1964) Identification of a spinocerebellar tract activated from forelimb afferents in the cat. Acta Physiol. Scand. 62: 125-136.

Piepmeier, J. M., J. S. Kauer, and C. A. Greer (1983) Laminar distributions of 2-deoxyglucose uptake in the rat spinal cord following electrical stimulation of the sciatic nerve. Brain Res. 259: 167-171.

Proshansky, E., J. S. Kauer, W. S. Stewart, and M. D. Egger (1980) $2-[14 \mathrm{C}]$ deoxyglucose uptake in the cat spinal cord during sustained and habituated activity in the plantar cushion reflex pathway. J. Comp. Neurol. 194: 505-517.

Rapoport, S. I., K. Ohno, and W. J. Schwartz (1978) Activity-related regional uplake of [14C]deoxyglucose by rat quadriceps femoris muscle. Exp. Neurol. 60: 168-174.

Rinvik, E., and F. Walberg (1975) Studies on the cerebellar projections from the main cuneate and external cuneate nuclei in the cat by means of retrograde axonal transport of horseradish peroxidase. Brain Res. 95: 371-381.

Sanderson, K. J., W. Welker, and G. M. Shambes (1984) Reevaluation of motor cortex and of sensorimotor overlap in cerebral cortex of albino rats. Brain Res. 292: 251-260.

Sasaki, K., Y. Matsuda, S. Kawaguchi, and N. Mizuno (1972) On the cerebello-thalamo-cerebral pathway for the parietal cortex. Exp. Brain Res. 16: 89-103.

Schim, J., P. Lyden, and F. R. Sharp (1981) Increased subcortical and laminar cortical 2-deoxy[14C]glucose uptake during cerebellar stimulation. Exp. Neurol. 74: 499-518.

Schoppmann, A., and M. P. Stryker (1981) Physiological evidence that the 2-deoxyglucose method reveals orientation columns in cat visual cortex. Nature 293: 574-576.

Schwartz, W. J., C. B. Smith, L. Davidsen, H. Savaki, L. Sokoloff, M. Mata, D. J. Fink, and H. Gainer (1979) Metabolic mapping of functional activity in the hypothalamo-neurohypophysial system of the rat. Science 205: 723-725.

Shambes, G. M., J. M. Gibson, and W. Welker (1978) Fracture somatotopy in granule cell tactile areas of rat cerebellar hemispheres revealed by micromapping. Brain Behav. Evol. 15: 94-104.

Sharp, F. R., and M. F. Gonzalez (1985) Multiple vibrissae sensory regions in rat cerebellum: A (14C)2-deoxyglucose study. J. Comp. Neurol. 234: 489-500.

Sharp, F. R., and A. F. Ryan (1984) Regional (14C)2-deoxyglucose uptake during forelimb movements evoked by rat motor cortex stimulation: Pons, cerebellum, medulla, spinal cord, muscle. J. Comp. Neurol. 224: 286-306.

Sharp, F. R., T. S. Kilduff, S. Bzorgchami, H. G. Heller, and A. F. Ryan 
(1983) The relationship of local cerebral glucose utilization to optical density ratios. Brain Res. 263: 97-103.

Shimazu, H., N. Yanagisawa, and B. Garoutte (1965) Cortico-pyramidal influences on thalamic somatosensory transmission in the cat. Jpn. J. Physiol. 16: 42-60.

Singer, W. (1977) Control of thalamic transmission by corticofugal and ascending reticular pathways in the visual system. Physiol. Rev. 57: 386-413.

Sokoloff, L. (1979) The [14C]deoxyglucose method: Four years later. Acta Neurol. Scand. (Suppl. 72), 60: 640-649.

Sokoloff, L. (1984) Metabolic Probes of Central Nervous System Activity in Experimental Animals and Man. Magnes Lecture Series, Vol. 1 , Sinauer, Sunderland, MA.

Strick, P. L. (1976) Activity of ventral thalamic neurons during arm movement. J. Neurophysiol. 39: 1032-1044.

Theurich, M., C. M. Müller, and H. Scheich (1984) 2-Deoxyglucose accumulation parallels extracellular recorded spike activity in the avian auditory neostriatum. Brain Res. 322: 157-161.

Toga, A. W., and R. C. Collins (1981) Metabolic response of optic centers to visual stimuli in the albino rat: Anatomical and physiological considerations. J. Comp. Neurol. 199: 443-464.
Tomasulo, K. C., and R. Emmers (1970) Spinal afferents to SI and SII of the rat thalamus. Exp. Neurol. 26: 482-497.

Toop, J., R. E. Burke, R. P. Dum, M. J. O'Donovan, and C. B. Smith (1982) 2-Deoxyglucose autoradiography of single motor units: Labeling of individually acutely active muscle fibers. J. Neurosci. Methods $5: 283-289$.

Valverde, F. (1966) The pyramidal tract in rodents. A study of its relations with the posterior column nuclei, dorsalateral reticular formation of the medulla oblongata, and cervical spinal cord. $Z$. Zellforsch. 71: 297-363.

Welker, C., and M. M. Shinha (1972) Somatotopic organization of SmII cerebral cortex in albino rat. Brain Res. 37: 132-136.

Yamamoto, T., S. Kawaguchi, and A. Samejima (1979) Electrophysiological studies on the cerebellocerebral projection in the rat. Exp. Neurol. 63: 545-558.

Yarowsky, P., M. Kadekaro, and L. Sokolof (1983) Frequency-dependent activation of glucose utilization in the superior cervical ganglion by electrical stimulation of cervical sympathetic trunk. Proc. Natl. Acad. Sci. USA 80: 4179-4183. 